\title{
Política de Inovação, Proteção do Conhecimento e Empreendedorismo: um estudo da relação entre a Universidade Estadual de Londrina e o setor produtivo
}

\author{
Innovation Policy, Knowledge Protection and Entrepreneurship: a study \\ of the relationship between the State University of Londrina and the \\ productive sector
}

\author{
Mario Cesar Lobo Junior ${ }^{1}$ \\ Letícia de Souza Baddauy ${ }^{1}$ \\ ${ }^{1}$ Universidade Estadual de Londrina, Londrina, PR, Brasil
}

\begin{abstract}
Resumo
O presente estudo tem por objetivo apresentar as principais atividades de inovação e pesquisa científica e tecnológica desenvolvidas pela Universidade Estadual de Londrina e sua relação com o setor produtivo, sob a ótica da teoria da Hélice Tríplice. A partir da análise de dados do NIT da universidade, é possível entender quais medidas vêm sendo tomadas para o pleno cumprimento dos compromissos assumidos com a Lei Federal de Inovação. Além disso, observa-se que, apesar de a UEL já estar inserindo a cultura de inovação em sua estrutura, falta uma política de inovação que regulamente suas relações institucionais com as empresas. $\mathrm{O}$ artigo ainda conclui que a quebra de barreiras para a promoção da inovação precisa ser desenvolvida, antes de tudo, dentro da própria universidade.
\end{abstract}

Palavras-chave: Universidade Empreendedora. Política de Inovação. Propriedade Intelectual.

\begin{abstract}
This study aims to present the main activities of innovation and scientific and technological research developed by the State University of Londrina and its relationship with the productive sector, from the perspective of the Triple Helix theory. By analyzing the university's NIT data, it is possible to understand what measures have been taken to fully comply with the commitments assumed under the Brazilian Innovation Law. Furthermore, it notes that, although the UEL is already inserting the culture of innovation into its structure, it lacks an innovation policy that regulates the institutional relations with the businesses. The article also concludes that the breaking down of barriers to promote innovation needs to be developed, first, within the university itself.
\end{abstract}

Keywords: Entrepreneurial University. Innovation Policy. Intellectual Property.

Área Tecnológica: Políticas de Inovação. Proteção do Conhecimento. Ambientes Inovadores. 


\section{Introdução}

As relações comerciais da contemporaneidade são marcadas pela necessidade de busca por soluções mais rápidas e acessíveis, com baixo custo de produção e constante aprimoramento de tecnologias. Não é novidade que governo e indústria têm reafirmado seus papéis históricos de mútua assistência para garantir o desenvolvimento local e regional, seja por meio da concessão de subsídios e de diminuição de impostos, seja pelo investimento em infraestrutura e manutenção do patrimônio público por meio de parcerias. É num cenário como esse, marcado pelo protagonismo de atores já conhecidos pelo mercado, que a relação se expande e entra em cena uma das instituições empreendedoras mais importantes dos últimos anos: a universidade.

Com a entrada em vigor da Lei Federal de Inovação (Lei n. 10.973, de 2 de dezembro de 2004), a academia, antiga aliada da produção do conhecimento aplicado no mercado e nas relações público-privadas, assume uma nova e grandiosa responsabilidade, caracterizada pelo compromisso com o desenvolvimento científico e tecnológico por meio do estreitamento de laços e quebra de barreiras institucionais, qual seja, a de gestora de um grande ambiente inovador.

Para além do eixo de sustentação ensino-pesquisa-extensão, as universidades têm buscado incessantemente não apenas produzir conhecimento, mas também convertê-lo em possíveis soluções a demandas pontuais e em conteúdo econômico (ETZKOWITZ; ZHOU, 2017). Essa é uma das bases da relação de troca firmada com a sociedade e, mais especificamente, com o setor produtivo. A relação sinalagmática de outrora se converte em interdependência e estímulo ao empreendedorismo inovador, com vistas à proteção da propriedade intelectual e à transferência das tecnologias desenvolvidas dentro do ambiente acadêmico.

A expansão dessa seara, por sua vez, traz o caráter de dependência por ser condicionada a uma forte política de inovação que se adeque às legislações federal e estadual; à atuação de um Núcleo de Inovação Tecnológica (NIT) que proteja o conhecimento ali produzido e promova a aproximação da Instituição Científica e Tecnológica (ICT) com a sociedade; e, ainda, à presença de uma incubadora que ofereça suporte a empresas inovadoras criadas e desenvolvidas no seio da universidade.

Nessa perspectiva é que se busca apontar o papel fundamental das políticas de inovação, mais detidamente a proposta para a Universidade Estadual de Londrina (UEL), como amparo jurídico às múltiplas ações de que depende seu processo de inovação. Do mesmo modo, a reserva de um capítulo especial no instrumento jurídico referindo-se às chamadas "empresas nascentes de base tecnológica", ou seja, àqueles empreendimentos incubados em organização gerenciada pela universidade - no caso da UEL, sua Incubadora Internacional de Empresas de Base Tecnológica (INTUEL) - aponta para a crescente necessidade das Instituições de Ciência e Tecnologia (ICTs) se adequarem às suas próprias demandas e às de uma sociedade que constantemente busca por soluções mais avançadas e eficazes. Tal fato reforça o papel empreendedor da universidade.

Além disso, cumpre dedicar um espaço deste estudo aos meios que ofereçam sustentação $e$ interliguem as agências de inovação, na figura do NIT, aos demais setores da universidade, posto que a elas cabe a atribuição de executar a política de inovação e atender ao eixo ensino-pesquisa-extensão dessas instituições. A partir dos estudos de Etzkowitz (2013), Zhou (2017) e Guedes (2018), este artigo pretende apontar a crescente aplicação do modelo de hélice tríplice 
aos ambientes inovadores, com foco na atuação da UEL para o desenvolvimento de Londrina e região, mesmo sem a presença de uma política de inovação.

\section{Metodologia}

A fim de obter as conclusões e as contínuas problematizações acerca do tema tratado no presente artigo, utilizou-se da pesquisa exploratória, com pesquisa bibliográfica e o estudo de caso da Universidade Estadual de Londrina. A princípio, foram selecionadas fontes primárias e secundárias aplicáveis, como as legislações federal e estadual, que regem as atividades de inovação e pesquisa científica e tecnológica, e as normativas internas da universidade.

Para o levantamento dos artigos, foram utilizadas as bases de dados da Sage Journals, plataforma Scielo e Portal de Periódicos da CAPES, por meio da busca específica pelos estudos desenvolvidos por Henry Etzkowitz sobre a teoria da Hélice Tríplice e a universidade empreendedora. Já a dissertação de mestrado de Isabela Guedes (2018) e os livros consultados foram selecionados pela profundidade com que abordam pelo menos uma das três frentes do artigo: o modelo da hélice tríplice; o papel dos Núcleos de Inovação Tecnológica das ICTs; e a interdependência entre as políticas de inovação e os ambientes inovadores.

$\mathrm{O}$ critério de inclusão respeitou estudos que (i) fizessem menção aos conceitos abordados em seu título e resumo; (ii) tivessem sido publicados após o ano de criação do NIT da UEL; e (iii) tratassem da relação entre as ICTs e os setores público e privado.

A partir da revisão da literatura e da delimitação do problema de pesquisa, foram acessados relatórios que trouxessem dados aptos a dialogar com o histórico de atividades de proteção do conhecimento desempenhadas pela UEL. Esses relatórios foram extraídos dos sites da universidade e de associações externas de referência, como o FORTEC, e de documentos não publicados produzidos pelo NIT.

O estudo das obras de autores pioneiros nos temas abordados, a exemplo de Guedes (2018), Etzkowitz (2013) e Zhou (2017), contribuiu para a fundamentação dos objetivos desta pesquisa, resultando numa verdadeira análise lógico-sistêmica entre as linhas de desenvolvimento, a partir de um método conceitual-analítico. O método utilizado apresenta certa liberdade de pensamento por não entregar respostas prontas ou potencialmente permanentes e uniformes, mas em constante movimento e transformação pela própria natureza do objeto de estudo.

\section{Resultados e Discussão}

A análise do desenvolvimento das ações voltadas para a proteção e a difusão do conhecimento pela UEL, ainda antes da Lei Federal de Inovação e da posterior criação de seu NIT, demonstram que a cultura de inovação vem sendo implementada há algum tempo pela universidade.

A pesquisa científica e tecnológica de ponta, o estabelecimento de relações com os setores público e privado, inclusive na forma de cooperações, e a transferência de tecnologia dentro de um ambiente inovador e que estimula o empreendedorismo são aspectos importantes que ora precisam ser entendidos separadamente, ora relacionados como partes de um só processo. 
O modelo da Hélice Tríplice, o papel fundamental dos NITs e a relação entre as políticas de inovação e os ambientes inovadores são eixos gerais que serão abordados de acordo com o contexto em que se apresentam, ou podem se apresentar, na universidade.

\subsection{Hélice Tríplice: o modelo universal de inovação além da teoria}

O nível de desenvolvimento socioeconômico mundial nos dias de hoje é fortemente marcado por sucessivos investimentos em tecnologia, inovação, geração e exploração de riquezas, criação de indústrias e soluções para problemas de níveis local, regional, nacional e internacional.

Nesse cenário, governo e indústria, velhos conhecidos do mundo das relações institucionais, passam a dividir o protagonismo e a responsabilidade pelo crescimento econômico com um dos mais importantes atores da esfera social: a universidade.

As antigas relações bilaterais e ambivalentes assumidas pelos setores público e privado, datadas do século XVIII e baseadas em relações ora de mútua assistência ora de mútua repulsão, dão lugar a um domínio triplo de ação, marcado pela interação interdependente de pesquisa e produção de conhecimento, investimento e aplicação dos resultados obtidos como resposta a demandas setoriais.

Governo, indústria e universidade assumem um compromisso de responsabilidade compartilhada com a inovação e com o empreendedorismo por meio de uma metodologia de atuação que busca conhecer as necessidades do ambiente em que estão inseridos para entregar produtos e tecnologias cada vez mais satisfatórios, conhecida por Hélice Tríplice (ETZKOWITZ; ZHOU, 2017). Mesmo sendo cada qual oriundo de um espectro de atividades distintas, a relação travada entre eles apresenta porosidades que não mais os engessa e os isola em campos tradicionalmente ocupados.

A universidade, por exemplo, adentra o mundo empreendedor e nele imerge com vistas a estimular a inovação e o desenvolvimento tecnológico, convertendo aquilo que produz - o conhecimento - em capital economicamente aplicável ${ }^{1}$. $\mathrm{O}$ comprometimento com o princípio constitucional de ensino, pesquisa e extensão ${ }^{2}$ supera suas barreiras territoriais e ganha novos significados e espaços que consignam a indissociabilidade entre seus pilares de sustentação.

Etzkowitz (2013) chama essa mudança de paradigma de "modelo de Universidade Empreendedora", que abrange três fases de evolução não necessariamente lineares para atingir o objetivo de desenvolvimento econômico regional. Num primeiro momento, a instituição passa a delimitar suas prioridades e a expandir sua gama de interações e de fontes de captação de recursos para além de tão somente os setores público ou privado isoladamente. Em seguida, passa a comercializar e a negociar a propriedade intelectual decorrente de suas pesquisas com empresas, as quais, em muitos casos, buscam especializar-se e entregar novos produtos ao mercado como meio de aumento da competitividade. É justamente nesse ponto que surge o papel fundamental da transferência de tecnologia.

Além disso, ainda nesta fase, a universidade começa a desenhar a formação de grupos de estudo e pesquisa que poderão evoluir no âmbito acadêmico para se tornarem, posteriormente, empresas, isto é, trata-se de uma transformação do conhecimento em algo economicamente

\footnotetext{
${ }^{1}$ É o que Etzkowitz e Zhou (2017) chamam de "traduzir conhecimento em atividade econômica"

${ }^{2} \mathrm{O}$ artigo 207 da Constituição da República Federativa do Brasil assegura que "As universidades gozam de autonomia didático-científica, administrativa e de gestão financeira e patrimonial, e obedecerão ao princípio de indissociabilidade entre ensino, pesquisa e extensão" (BRASIL, 1988).
} 
aplicável, como já mencionado, e que passará a estabelecer relações com empresas e órgãos preexistentes.

Segundo o pesquisador, é na terceira e última fase $e^{3}$ que a universidade assume a responsabilidade de firmar parcerias com os outros atores na busca incessante de melhoria do seu ambiente de inovação. Toda essa atuação empreendedora, portanto, depende de duas forças motrizes principais: (i) a abertura da universidade para inserção do empreendedorismo como um dos meios de avanço tecnológico e crescimento institucional; e (ii) a busca, principalmente de empresas, por novas tecnologias e soluções para problemas contemporâneos.

Na realidade brasileira, é a Lei n. 10.973, de 2 de dezembro de 2004, também conhecida como Lei Federal de Inovação, que estabelece o incentivo à inovação e à pesquisa científica $e$ tecnológica e regulamenta a formação dessas redes de interação público-privadas no ambiente produtivo (BRASIL, 2004). O desenvolvimento econômico e social pautado em estratégias de inovação tecnológica e a busca por atividades de transferência de tecnologia e de constituição de ambientes favoráveis à inovação se tornam princípios ${ }^{4}$ inafastáveis quando da realização de atividades conjuntas, o que abre caminho para a implementação de uma verdadeira cultura de inovação.

A universidade passa a ser designada Instituição Científica, Tecnológica e de Inovação (ICT), assentando a importância da inovação em sua missão institucional. Logo, é cabível incluir a inovação como prioridade equivalente ao rol de pilares institucionais, junto com a pesquisa, o ensino e a extensão. No campo fático, não é difícil encontrar exemplos que corroborem essa aliança, como bem pontuou Etzkowitz (2013, p. 488, tradução nossa):

[...] algumas escolas com recursos modestos, como o Arizona State e a Universidade de Utah, que tornaram a transferência de tecnologia e a formação de empresas uma prioridade igual a educação e pesquisa, alcançaram taxas mais altas de valorização do que muitos de seus concorrentes ricos em recursos.

O modelo da Hélice Tríplice não se limita a conceituar as diferentes formas de relacionamento entre governo, indústria e universidade. Ela avança para o campo concreto na medida em que acrescenta a inovação ao ensino, pesquisa e extensão como um resultado híbrido, constituído pela indissociabilidade dessa tríade por seus próprios elementos e catalisado pela cultura empreendedora nascente.

Esse paradigma vem sendo empregado paulatinamente em diferentes países, com denominações das mais variadas, mas com o mesmo núcleo: a formação de parcerias estratégicas para o desenvolvimento. Ambientes inovadores, com profundo aparato tecnológico e pesquisa de ponta, são construídos a partir da interação governo-universidade-empresas, que traz benefícios para todos os envolvidos. Simultaneamente, o governo garante o desenvolvimento social e econômico, as empresas utilizam-se da mais alta tecnologia para entregar soluções confiáveis $e$ inovadoras a problemas hodiernos, e a universidade faz um intercâmbio de conhecimentos, produtos, processos e serviços, atendendo à sociedade e enxergando a si mesma como uma

\footnotetext{
${ }^{3}$ Cumpre destacar que, para Etzkowitz (2013), sequências não lineares e mesmo reversas podem ser identificadas nos processos de empreendedorismo das universidades, e que igualmente podem atingir os objetivos aos quais se propõem.

${ }^{4}$ Consta do parágrafo único do artigo $1^{\circ}$ da Lei n. 10.973/2004 os princípios a serem observados para a realização das medidas regulamentadas. Na mesma vereda, foi a Lei n. 13.243/2016, conhecida também como Marco Legal de CT\&I, que inseriu, além desses princípios, a previsão legal de instituição da Política de Inovação das Instituições Científicas, Tecnológicas e de Inovação (ICT).
} 
instituição empreendedora, responsável por dar continuidade aos projetos iniciados dentro de seu domínio.

\subsection{O Direito à Proteção do Conhecimento: breves considerações acerca da atuação dos Núcleos de Inovação Tecnológica}

O advento da Lei Federal de Inovação trouxe profundas mudanças estruturais que foram absorvidas pelas universidades, como sua reconfiguração em Instituições Científicas, Tecnológicas e de Inovação (ICT), as quais incluem em seus objetivos sociais ou estatutários a pesquisa básica ou aplicada, de caráter científico ou tecnológico, e o desenvolvimento de tecnologias, produtos, processos e serviços.

Nessa vereda, as ICTs passam a assumir uma maior responsabilidade, que não se limita apenas à produção do conhecimento, mas, também, à proteção e posterior transferência e comercialização. É bem verdade que de nada adiantaria investir fortemente em pesquisa científica e tecnológica se toda a produção acadêmica estivesse (i) sob ameaça de violação de direitos da propriedade intelectual; e (ii) limitada aos laboratórios e salas de aulas da universidade, sem um maior contato com o público externo.

É partindo desse ponto que surge a conceituação e a regulamentação das atividades dos Núcleos de Inovação Tecnológica (NIT), estruturas centralizadoras do direito de proteção ao conhecimento de que dispõem as instituições e que apresentam, entre outras finalidades, o grande papel de gestoras de sua política de inovação, conforme preceitua o artigo 16 da Lei de Inovação ${ }^{5}$. Por conseguinte, são originárias dessa atuação principal a avaliação da conveniência de promoção e estímulo para a obtenção e manutenção de títulos de propriedade intelectual, a assistência a inventores independentes, o desenvolvimento de estudos e estratégias de transferência do conhecimento e inovação da ICT para setores externos e a aproximação das universidades com as empresas.

De acordo com Trzeciak, Coral e Pereira (2010), muitos dos NITs já existiam anteriormente à promulgação da lei, porém com outras denominações, a exemplo de agências de inovação tecnológica, escritórios de transferência de tecnologia, escritórios de propriedade intelectual etc. Entretanto, esses casos podem ser considerados isolados, uma vez que os dados do Relatório anual da Pesquisa FORTEC de Inovação - Ano Base 2017 apontam que a idade média dos núcleos de inovação das ICTs pesquisadas, de todas as regiões do Brasil, é de apenas 9,7 anos, ou seja, há um significativo intervalo entre o início das atividades de proteção da propriedade intelectual e a promulgação da Lei de Inovação, o que pode indicar a necessidade de adequação das ICTs à lei vigente (TORKOMIAN, 2018).

O NIT alvo do presente estudo é o da Universidade Estadual de Londrina (UEL), que estampa exatamente a denominação conferida por Trzeciak, Coral e Pereira (2010): Agência de Inovação Tecnológica. De acordo com Guedes (2018), o pedido de proteção mais antigo da instituição data do ano de 1989, ou seja, muito antes de haver uma imposição legal, a UEL já traçava suas primeiras estratégias de proteção ao conhecimento, inclusive permitindo a participação de seus docentes e servidores técnico-administrativos no resultado financeiro de patentes

5 "Para apoiar a gestão de sua política de inovação, a ICT pública deverá dispor de Núcleo de Inovação Tecnológica, próprio ou em associação com outras ICTs" (BRASIL, 2004) 
da universidade que viessem a ser exploradas ${ }^{6}$. Tal atuação permitiu que, desde o início das atividades de sua Agência de Inovação, o número de patentes, marcas, desenhos industriais e programas de computador depositados totalizasse 527 pedidos (AINTEC, 2019).

A Agência de Inovação Tecnológica (AINTEC) foi criada por meio da Resolução do Conselho Universitário (CU) n. 65/2008 e teve seu regimento interno aprovado no ano seguinte, por meio da Resolução CU n. 263. Em 2017, sobreveio a Resolução CU n. 034 que alterou o regimento interno da agência e definiu sua estrutura orgânica ${ }^{7}$, formada pelas divisões de Propriedade Intelectual, de Transferência de Tecnologia e da Incubadora Internacional de Empresas de Base Tecnológica (INTUEL), secretaria executiva, direção e conselhos diretor e técnico. Este último, o Conselho Técnico, foi inserido, vale frisar, para ser o responsável pela deliberação de assuntos urgentes, como explicado por Guedes (2018), e para opinar e exarar parecer acerca da conveniência da proteção às criações e às invenções geradas na $\mathrm{UEL}^{8}$.

Outro ponto que merece destaque é a aproximação da UEL com o setor produtivo por meio de seu NIT. Diferentemente do que se costuma pensar, o estabelecimento de sólidas relações institucionais e de mútua parceria entre a ICT e as empresas, ou mesmo entre a primeira e o governo, imprescinde de uma atitude mais proativa da academia, que precisa desenvolver estudos e estratégias de captação de demandas, por meio da detecção de problemas locais e regionais, para que volte a atenção de potenciais cooperadores às soluções desenvolvidas.

Uma dessas atitudes que vêm sendo tomadas pela agência de inovação da UEL é a prospecção de parcerias por meio de uma Vitrine Tecnológica9 ${ }^{9}$. No site oficial do NIT, entidades públicas e privadas têm acesso a uma gama de patentes e registros de titularidade da universidade, as quais estão disponíveis para licenciamento, transferência e comercialização, consignando a missão assumida pela ICT no artigo $1^{\circ}$ da Lei de Federal de Inovação ${ }^{10}$ e a faculdade que lhe foi oportunizada pelo Decreto n. 9.283, de 7 de fevereiro de 2018, que regulamenta a Lei Federal de Inovação, e pela Lei de Inovação do Estado do Paraná (Lei n. 17.314, de 24 de setembro de 2012).

Trzeciak, Coral e Pereira (2010) pontuam que o processo de comercialização e valoração de uma tecnologia vai desde a escolha e identificação dos alvos potenciais até a divulgação das tecnologias, negociação e posterior gestão dos contratos. Para tanto, uma série de diretrizes deve ser observada. A título de exemplificação, a estrutura e a organização do NIT, a gestão do conhecimento, o investimento em recursos humanos e a difusão da cultura de inovação são partes de um todo sistêmico cujo principal objetivo é o desenvolvimento econômico e social regional, que, por sua vez, está irrestritamente condicionado a mecanismos eficazes de divulgação científica, entre os quais pode se inserir a Vitrine Tecnológica. Essa competência de tamanha importância foi igualmente regulamentada pela Lei de Inovação, mais especificamente em seu artigo $16, \S 1^{\circ}$, inciso $\mathrm{V}$.

\footnotetext{
${ }^{6}$ A Resolução n. 1.312/1988, aprovada pelo Conselho de Administração da UEL em 28 de dezembro de 1988, previa a titularidade da universidade para as patentes desenvolvidas por seu quadro de funcionários e garantia a estes um percentual de participação nos recursos financeiros resultantes de licença, cessão ou transferência que variava entre $5 \%$ (cinco por cento) e $30 \%$ (trinta por cento), de acordo com o artigo $1^{\circ}$ e artigo $2^{\circ}$, inciso II respectivamente. É de se notar que a Lei Federal de Inovação, promulgada no ano de 2004, também garante o mínimo de $5 \%$ (cinco por cento) de participação nos ganhos econômicos auferidos pela ICT ao criador, conforme preconiza seu artigo 13.

${ }^{7}$ De acordo com o artigo $3^{\circ}$ da Resolução CU n. 034/2017, a AINTEC tem como objetivos "[...] a promoção do desenvolvimento científico e tecnológico, sua transferência para a sociedade, em especial para o setor produtivo, e o atendimento às demandas da sociedade relacionadas a atividades de ciência e tecnologia, com base nos princípios de incentivo à atividade inventiva e tecnológica" (UEL, 2017).

${ }^{8} \mathrm{~A}$ indicação dessa função como sendo do Conselho Técnico da agência de inovação atende a uma das competências atribuídas ao NIT e definida no artigo 16, $\S 1^{\circ}$, inciso IV, da Lei Federal de Inovação e artigo 17, § $1^{\circ}$, inciso IV, da Lei de Inovação do Estado do Paraná (Lei n. 17.314/2012).

${ }^{9}$ Site da Vitrine Tecnológica da Agência de Inovação Tecnológica da UEL. Disponível em: https://www.aintec.com.br/transferencia-de-tecnologia/2235-2/.

${ }^{10}$ Com alterações do Marco Legal de Ciência, Tecnologia e Inovação (Lei Federal n. 13.243, de 11 de janeiro de 2016).
} 
A transferência da tecnologia produzida na universidade é um dos maiores estímulos para a participação das ICTs no processo de inovação previstos legalmente. O investimento feito por uma empresa do setor privado em um produto, processo ou serviço devidamente protegido $e$ desenvolvido sob a mais avançada pesquisa científica e tecnológica, por exemplo, atenderá às exigências locais e regionais por novas tecnologias, promoverá a competitividade empresarial e a criação de novas empresas de base tecnológica e, a longo prazo, auxiliará no aumento das demandas por pesquisa e desenvolvimento.

Conforme acentuam Von Jelita et al. (2012, p. 132),

Num período mais longo, programas de transferência de tecnologia implicam em ganhos econômicos mais elevados uma vez que, após alavancar o setor de indústria, o próprio crescimento irá realimentar o fluxo de transferência, por gerar demanda para novas tecnologias.

Semelhante estímulo à inovação e ao desenvolvimento da cadeia produtiva é a prestação de serviços técnicos especializados por parte da ICT, baseada em atividades que envolvam a pesquisa científica e tecnológica no ambiente produtivo com vistas, também, a um aumento de competitividade entre as empresas (BRASIL, 2004). A UEL realizou, por exemplo, por intermédio de sua agência de inovação, 55 serviços laboratoriais somente no ano de 2019 (UEL, 2019), envolvendo laboratórios dos mais diversos centros de estudo, como o de Ciências Exatas (CCE), Ciências Biológicas (CCB) e Ciências Agrárias (CCA).

Há também as chamadas cooperações técnico-científicas e de inovação tecnológica que podem ser firmadas entre as ICTs e as instituições públicas e privadas. É justamente nesse ponto que costuma ser identificada uma atuação mais empreendedora da universidade ${ }^{11}$. $\mathrm{O}$ estabelecimento de um acordo de cooperação significa, segundo Bocchino et al. (2011, p. 75), que, no desenvolvimento do projeto, não haverá partes, como em um contrato, mas parceiros que buscam um mesmo objetivo. Os autores assinalam que de um lado está quem possui recursos humanos e estruturas adequadas ao correto cumprimento das atividades de pesquisa e, de outro, quem possui interesse nos resultados que eventualmente serão obtidos, a partir da aplicação de recursos financeiros. Pontuam, ainda, a relevância do NIT como gestor das cooperações, principalmente no que diz respeito aos resultados da inovação, sendo certo que, na maioria dos casos, a tecnologia gerada estará sujeita à divisão em porcentagens do regime de titularidade e participação de cada parceiro ${ }^{12}$ (BOCCHINO et al., 2011).

\subsection{Política de Inovação e Ambientes Inovadores: uma relação de interdependência}

A Lei Federal de Inovação pode ser considerada um divisor de águas por regulamentar as estratégias de inovação das ICTs e estimular a criação e o desenvolvimento de um ecossistema propício à formação de empresas de base tecnológica. Entretanto, foi o Marco Legal de CT\&I

\footnotetext{
${ }^{11}$ Etzkowitz (2013, p. 507) conclui que a universidade empreendedora eleva os modelos acadêmicos de ensino e pesquisa a um nível maior de desenvolvimento com base numa relação de troca com a sociedade, visando à criação de empreendimentos econômicos e sociais para financiamento em larga escala do conhecimento científico produzido.

${ }^{12} \mathrm{~A}$ redação do artigo $9^{\circ}, \S 2^{\circ}$, da Lei de Inovação prescreve que a ICT e o cooperador deverão estabelecer em instrumento jurídico próprio a titularidade da propriedade intelectual e a participação de cada um nos resultados da exploração da criação resultante. É assegurado também o direito à exploração, ao licenciamento e à transferência de tecnologia.
} 
que inseriu, entre os compromissos assumidos pelas instituições de pesquisa, a necessidade de se instituir uma política de inovação. Nesse sentido:

A ICT de direito público deverá instituir sua política de inovação, dispondo sobre a organização e a gestão dos processos que orientam a transferência de tecnologia $e$ a geração de inovação no ambiente produtivo, em consonância com as prioridades da política nacional de ciência, tecnologia e inovação e com a política industrial e tecnológica nacional. (BRASIL, 2004, art. 15-A)

A política a que se refere o supracitado artigo estabelece diretrizes e objetivos de atuação institucional no ambiente produtivo no qual está inserida a ICT, prestação de serviços técnicos e gestão de incubadoras como meio de fomentar o empreendedorismo inovador, gerenciamento da propriedade intelectual e transferência de tecnologia da ICT e institucionalização e gestão de seu NIT (BRASIL, 2004), entre outros.

Do exposto, é possível entender que há uma verdadeira conjugação de esforços inter-relacionados e dependentes uns dos outros para a formação de ambientes promotores da inovação ${ }^{13}$. Uma economia baseada no conhecimento se torna realidade quando impulsionada pela universidade e sua natureza inovadora, trazendo benefícios para si e para a sociedade e aumentando a competitividade regional e local (ETZKOWITZ, 2013).

Isso é dizer que a partir do momento em que os atores da inovação passam a ter uma visão macro de sua esfera de atuação, não medindo esforços para a construção de ambientes inovadores, fica a concretização desse objetivo condicionada à existência de uma forte política de inovação, a qual estabelecerá e regulará os mecanismos a serem empregados. Um exemplo concreto disso é, novamente, o da UEL que, sendo uma ICT pública com o compromisso de incentivar a inovação e de atender ao disposto na Lei Federal de Inovação, assume aquela responsabilidade já discutida anteriormente: a de gerir um grande ambiente inovador.

Esse fenômeno de atuação universitária porosa, de constante troca de ações e conhecimentos com o setor privado, notadamente com o objetivo de empreender, foi apontado por Etzkowitz e Zhou (2017) como a fonte original do Vale do Silício. De acordo com os autores, as empresas que buscavam o crescimento econômico da região atuavam ativamente na entrega de demandas para a universidade, tanto que os professores à época envolvidos eram autorizados e incentivados, inclusive, a exercer uma dupla carreira, qual seja, a de docentes envolvidos com pesquisa tecnológica e a de participantes dessas empresas cooperadoras. Cumpre notar que esse avanço não é uma exclusividade do território norte-americano, porquanto a Lei de Inovação, em seu artigo 15, prevê a possibilidade de concessão de licença sem remuneração ao pesquisador público para a constituição de empresa com a finalidade de desenvolver atividades empresariais voltadas para a inovação ${ }^{14}$.

A Incubadora Internacional de Empresas de Base Tecnológica da UEL, de acordo com Guedes (2018), foi criada no ano de 2000, anteriormente à promulgação da Lei de Inovação,

\footnotetext{
${ }^{13} \mathrm{O}$ artigo $2^{\circ}$, inciso II, do Decreto n. 9.283/2018 conceitua esses ambientes como espaços favoráveis, no sentido lato, à inovação e ao empreendedorismo, reafirmando as características que Etzkowitz (2013) apontara para uma economia baseada no conhecimento, que articula empresas, sociedade e os diferentes níveis de governo. Há ainda acertado desmembramento entre os ecossistemas de inovação, que agregam infraestrutura adequada ao desenvolvimento do empreendedorismo, e os mecanismos de geração de empreendimentos. Este último definido como os meios de promoção de empreendimentos inovadores e de empresas nascentes de base tecnológica que buscam soluções para problemas e desafios sociais ou ambientais, envolvendo nesse conjunto complexo as incubadoras de empresas, aceleradoras de negócios, espaços para trabalho cooperativo e laboratórios de pesquisa e prototipagem de produtos e processos (BRASIL, 2018).

14 "A critério da administração pública, na forma do regulamento, poderá ser concedida ao pesquisador público, desde que não esteja em estágio probatório,

licença sem remuneração para constituir empresa com a finalidade de desenvolver atividade empresarial relativa à inovação". (BRASIL, 2004, art. 15)
} 
e atualmente está incorporada à estrutura orgânica de seu NIT ${ }^{15}$. Mais de 15 empresas já passaram pelo processo de incubação da INTUEL, sendo que no ano de 2016 foram gerados 55 empregos e faturado aproximadamente $\mathrm{R} \$ 1,6$ milhão (AINTEC, 2017). Tamanho foi o desenvolvimento econômico e organizacional, que algumas dessas empresas mergulharam a fundo no setor produtivo da cadeia nacional e, inclusive, internacional.

Muito embora esteja consignado o nível de crescimento das empresas incubadas na INTUEL, é necessário levantar a discussão acerca da inexistência, até o momento, de uma política de inovação para a UEL. Em estudo pioneiro sobre o assunto, Guedes (2018) delimita e analisa as principais ações que podem promover a atuação da UEL num campo que já é de seu conhecimento, mas que carece de regulamentação e, principalmente, comunicação entre os órgãos e as unidades institucionais envolvidos. Conforme exposto anteriormente, a interdependência assumida entre a política de inovação das universidades e a constituição de um ambiente inovador não possibilita a existência de um sem o outro. Novamente, Guedes (2018) apresentou uma minuta da política de inovação da UEL baseada na Lei Federal de Inovação, Lei de Inovação do Estado do Paraná e nas resoluções internas da ICT, restando disposto que:

[...] A Política de Inovação da UEL tem como objetivo estabelecer medidas de incentivo à inovação e à pesquisa científica, criando um ambiente favorável à criação de novos conhecimentos e sua transferência para a sociedade, regulamentando a proteção da propriedade intelectual, o licenciamento, a transferência de tecnologia, a prestação de serviço e a incubação de empresas no âmbito da instituição. (GUEDES, 2018, p. 63)

Um capítulo especial da referida minuta é dedicado às chamadas "empresas nascentes de base tecnológica", inseridas no contexto de fomento à atividade empreendedora assegurada pelo Decreto n. 9.283/2018. Nele, estão previstos os estímulos ao desenvolvimento das empresas incubadas na INTUEL por intermédio de uso de área individualizada, assessoria, incentivo $e$ monitoramento de seu desenvolvimento, troca de conhecimentos, incluída a cooperação com outras incubadoras, concessão de benefícios no que se refere à proteção de propriedade intelectual da empresa, à possibilidade de compartilhamento de uso de laboratório, entre outros.

Essa troca, que busca a mútua promoção do conhecimento, inovação e empreendedorismo entre a universidade e as empresas, apresenta verdadeiro cumprimento dos objetivos estabelecidos na Lei de Inovação. A INTUEL, por exemplo, ficou responsável por 28 dos 206 pedidos de patente depositados junto ao Instituto Nacional da Propriedade Industrial (INPI), pela Agência de Inovação Tecnológica da UEL, e por 44 pedidos de registro de marca, segundo dados do Relatório de Atividades 2014-2019 do Escritório de Propriedade Intelectual (AINTEC, 2019). Isso demonstra, mais uma vez, a preocupação simultânea de proteção do conhecimento desenvolvido e acessado pelas empresas e pela universidade e de fomento do empreendedorismo inovador, buscando novas soluções e enveredando esforços conjuntos para aplicação da tecnologia no mercado.

A importância de políticas de inovação para a construção e o aprimoramento de ambientes inovadores é reforçada, como no caso da INTUEL, pela presença de incubadoras híbridas que, criadas dentro da universidade, estabelecem uma relação de troca com os NITs e outros órgãos

\footnotetext{
${ }^{15}$ Compõe uma das atribuições da Agência de Inovação Tecnológica da UEL o estímulo, o apoio e o gerenciamento da criação e do desenvolvimento de empreendimentos e de empresas de base tecnológica por meio da INTUEL (UEL, 2017).
} 
da estrutura acadêmica. Essa relação é tão fundamental para ambas as partes que, insista-se, carece de regulamentação interna para a correta utilização dos recursos e dos meios de parcerias público-privadas. A ausência de uma normativa que assegure os interesses de ambas as cooperadoras $^{16}$ pode desestimular o processo inovador, porquanto maculado de incertezas $e$ de divulgação precária do conhecimento.

Na minuta da Política de Inovação da UEL, desenvolvida por Guedes (2018), há previsão de que as "empresas nascentes de base tecnológica", potencialmente incubadas na INTUEL, não só compartilhem a área de uso com o NIT, mas também celebrem acordos de cooperação com a UEL, troquem informações e conhecimentos com unidades da Universidade e com outras incubadoras e aceleradoras, apoiem a identificação de docentes e pesquisadores que possam auxiliar o aprimoramento de suas tecnologias - ou, na ordem reversa, na identificação de pesquisadores que precisam de auxílio para o aprimoramento, divulgação e exploração das tecnologias desenvolvidas pela Universidade, entre outros. Nesse sentido, veja-se:

Art. 25 - A UEL poderá apoiar, por meio da Incubadora Internacional de Empresas de Base Tecnológica da UEL (INTUEL), empresas nascentes de base tecnológica, observada a legislação pertinente, visando à promoção da inovação, do empreendedorismo $e$ do desenvolvimento do Estado, oferecendo, entre outros, os seguintes benefícios: [...]. (GUEDES, 2018, p. 73)

Tamanho é o compromisso com o desenvolvimento econômico e social locais, que foi montado um grupo de empresas incubadas e já graduadas ${ }^{17}$ que atendem especificamente às demandas do setor agrícola, o Vertical Agro INTUEL, segundo dados do relatório INTUEL Informações 2014-2019. Essas empresas de base tecnológica atendem desde o pequeno produtor até os proprietários de modernas máquinas agrícolas da região, por meio do desenvolvimento de novas tecnologias de sementes, fertilizantes e softwares de gestão e monitoramento das condições climáticas (INTUEL, 2019). O acesso ao conhecimento produzido dentro das salas de aula e de laboratórios da universidade, por exemplo, figura como pressuposto a ser respeitado por ambos os partícipes do processo de inovação, sendo certo que a troca de experiências entre as necessidades do mercado - detidamente o setor agrícola - e as pesquisas acadêmicas são força motriz do crescimento dessas empresas.

A busca pela transformação do conhecimento em renda que possa ser convertida para a manutenção da própria universidade, como no caso da prestação de serviços de laboratórios para empresas, anteriormente mencionada, estabelece inegável conexão com os estudos de Etzkowitz e Zhou (2017), vez que a universidade empreendedora, ao mesmo tempo em que trabalha para a comunidade e auxilia o setor produtivo, contribui para o seu próprio funcionamento, valendo-se de uma atuação que historicamente vem sendo desenvolvida: o conhecido eixo ensino-pesquisa-extensão, ao qual caberia incluir, com os fundamentos até então expostos, a inovação.

\footnotetext{
${ }^{16}$ É preferível designar a universidade e as empresas como cooperadoras, e não partes, por simples atendimento à estrutura inovadora que se deseja instituir dentro e fora do ambiente acadêmico. O uso da palavra "partes" revoca àquela relação sinalagmática que se reafirma estar superada, de prestação e contraprestação, com interesses díspares, o que não se espera. A busca por objetivos comuns é o que faz com que a relação tenha resultados positivos para ambas.

${ }^{17} \mathrm{O}$ termo graduada, para fins do processo ocorrido na INTUEL, se refere àquelas empresas de base tecnológica que passaram um determinado período de tempo incubadas, sendo assessoradas e passando por consultorias e monitoramentos frequentes de acordo com o modelo de gestão do Centro de Referência para Apoio a Novos Empreendimentos (CERNE). Essas empresas têm seu desenvolvimento econômico, atuação, produção tecnológica e rede de relacionamentos institucionais acompanhados pelo gerente da incubadora de modo a parametrizar as dificuldades e facilidades encontradas pelos empreendedores para elevarem o porte do negócio e firmarem sua posição no mercado.
} 


\section{Considerações Finais}

A inovação, por si só, carrega um amplo espectro de transformações institucionais e culturais. No Brasil, as discussões e os estudos acerca da introdução de um novo pensamento para o desenvolvimento científico e tecnológico, nos âmbitos governamental e civil, ainda sofrem com um profundo atraso. Nesse sentido, a Lei Federal de Inovação, vigente desde o ano de 2004, possui a missão de tentar alterar essa situação que impede os crescimentos econômico, social e educacional.

Muito embora possa ser considerada um avanço, a legislação não conseguirá, sozinha, atingir seus objetivos e garantir o cumprimento de seus princípios sem uma atuação mais proativa de todos os atores envolvidos na seara em que é aplicada. Como apresentado, governo e indústria reafirmaram seu vínculo preexistente com a produção e a solução de demandas por meio da abertura dessa relação para a entrada da universidade.

Contudo, ainda falta um pressuposto fundamental: a adoção da cultura de inovação pelas organizações, independentemente de sua atuação ser ou não voltada para as áreas científica e tecnológica. Experiências concretas descritas ao longo do presente artigo, como a do Vale do Silício ou da INTUEL, corroboram a necessidade de interação entre as esferas público-privadas para que esses obstáculos possam ser ultrapassados, mas não é apenas isso. Tais óbices só poderão ser efetivamente enfrentados se todo o conjunto social entender como sua a responsabilidade de introduzir mecanismos inovadores nas relações humanas, do trabalho, de pesquisa, ensino, produção e demais. Nas palavras de Augusto Nardes (2018):

[...] o Brasil apresenta um passivo nesse quesito [inovação tecnológica], que precisa urgentemente ser equacionado, sob pena de ficarmos eternamente a reboque das nações mais desenvolvidas, que alcançaram um crescimento sustentável de longo prazo graças à sua capacidade de realizar inovações, condutoras de novos ciclos tecnológicos que empurraram o crescimento mundial.

Alunos, professores e técnicos podem expandir e enriquecer seus estudos firmando parcerias de mútua cooperação com empresas, órgãos públicos ou outras universidades. Os objetivos desse processo, anteriormente divergentes, constituem-se os mesmos, na medida em que a academia também vê no cooperador um potencial gerador de conhecimento. Tudo isso está intrinsecamente condicionado à adoção da cultura de inovação.

Por meio dos estudos apresentados, pode-se concluir que, na UEL, por exemplo, a cultura de inovação vem sendo implementada muito antes do advento da Lei Federal de Inovação. Data de 1989 o pedido de proteção de propriedade intelectual mais antigo da universidade, o que demonstra sua nascente preocupação com o que é desenvolvido e produzido por seu corpo acadêmico e técnico. Até a regulamentação de seu NIT, 20 anos após o pedido mais antigo, muitos foram os avanços da instituição para reforçar seu compromisso com a inovação.

É nesse ponto que o presente estudo conclui que essa mudança de paradigma está condicionada à presença de uma forte política de inovação no âmbito da UEL, para que a ICT envolva toda a comunidade acadêmica. Isso significa que a cultura de inovação deve ser difundida desde a concepção da pesquisa até a gestão dos contratos de transferência de tecnologia ou de cooperação. Em outras palavras, a inovação precisa estar inserida do início ao fim do pro- 
cesso. São esses mecanismos os responsáveis por aproximar aqueles que fazem parte do pacto firmado na Lei de Inovação, como é o caso da relação entre a universidade e as empresas de base tecnológica da INTUEL.

Nesse sentido, embora a UEL venha perseguindo estratégias que dialogam com a Lei Federal de Inovação há muito, somente sob a égide de (i) uma política de inovação que regulamente suas atividades e (ii) uma cultura de inovação que facilite a comunicação entre os órgãos que a compõe do início ao fim do processo é que a universidade poderá quebrar as barreiras institucionais e aprimorar ainda mais seu compromisso com a pesquisa científica $e$ com o desenvolvimento econômico e social de Londrina e região.

É preciso, em suma, compreender que inovação não é um setor, não está restrita a um determinado projeto de pesquisa, não é algo apartado do cotidiano, mas sim é um modo de pensar e de agir que necessita permear todas as atividades de ensino, pesquisa e extensão, sendo crucial para a própria continuidade das Universidades, agora vistas como verdadeiros Institutos de Ciência e Tecnologia.

\section{Referências}

AINTEC - AGÊNCIA DE INOVAÇÃO TECNOLÓGICA DA UEL. Relatório de Atividades: Escritório de Propriedade Intelectual: 2014-2019. Londrina: AINTEC, 2019. (Documento não publicado).

AINTEC - AGÊNCIA DE INOVAÇÃO TECNOLÓGICA DA UEL. Relatório de Atividade da Agência de Inovação Tecnológica da UEL - AINTEC: órgãos de apoio. Londrina: AINTEC, 2017. Disponível em: http://www.uel.br/proplan/novo/pages/arquivos/orgaos/AINTEC.pdf. Acesso em: 5 jul. 2019.

BOCCHINO, Leslie de Oliveira et al. Propriedade Intelectual: conceitos e procedimentos. 2. ed. Florianópolis: Imprensa Universitária - UFSC, 2011.

\section{BRASIL. Constituição (1988). Constituição da República Federativa do Brasil de}

1988. Disponível em: http://www.planalto.gov.br/ccivil_03/Constituicao/Constituicao.htm. Acesso em: 8 jul. 2019.

BRASIL. Decreto n. 9.283, de 7 de fevereiro de 2018. Regulamenta a Lei n. 10.973, de 2 de dezembro de 2004, a Lei n. 13.243, de 11 de janeiro de 2016, o art. 24 , $\S 3^{\circ}$, e o art. 32 , $\S 7^{\circ}$, da Lei n. 8.666, de 21 de junho de 1993, o art. $1^{\circ}$ da Lei n. 8.010, de 29 de março de 1990, e o art. $2^{\circ}$, caput, inciso I, alínea "g", da Lei n. 8.032, de 12 de abril de 1990, e altera o Decreto n. 6.759, de 5 de fevereiro de 2009, para estabelecer medidas de incentivo à inovação e à pesquisa científica e tecnológica no ambiente produtivo, com vistas à capacitação tecnológica, ao alcance da autonomia tecnológica e ao desenvolvimento do sistema produtivo nacional e regional. Presidência da República, Brasília, DF, 7 fev. 2018. Disponível em: http://www.planalto.gov.br/ccivil_03/_ato20152018/2018/decreto/d9283.htm. Acesso em: 11 jul. 2019.

BRASIL. Lei n. 10.973, de 2 de dezembro de 2004. Dispõe sobre incentivos à inovação e à pesquisa científica e tecnológica no ambiente produtivo e dá outras providências. Presidência da República, Brasília, DF, 2 dez. 2004. Disponível em: http://www.planalto.gov.br/ccivil_03/_ato2004-2006/2004/ lei/110.973.htm. Acesso em: 8 jul. 2019.

ETZKOWITZ, H. Anatomy of the entrepreneurial university. Social Science Information, 
Thousand Oaks, v. 52, n. 3, p. 486-511, 2013.

ETZKOWITZ, Henry; ZHOU, Chunyan. Hélice Tríplice: inovação e empreendedorismo universidadeindústria-governo. Estudos Avançados, São Paulo, v. 31, n. 90, p. 23-48, maio, 2017. Disponível em: http://www.scielo.br/scielo.php?script=sci_arttext\&pid=S0103-40142017000200023\&lng=en\& nrm=iso. Acesso em: 29 jun. 2019.

GUEDES, Isabela Lima Braz. Proposta de política de inovação para a Universidade Estadual de Londrina. 2018. Dissertação (Mestrado) - Universidade Estadual de Maringá, Maringá, PR, 2018.

INTUEL - INCUBADORA INTERNACIONAL DE EMPRESAS DE BASE TECNOLÓGICA DA UEL. Informações (2014 a 2019). Londrina: INTUEL, 2019. (Documento não publicado)

NARDES, Augusto. Prefácio. In: VALE, Horácio. Princípios jurídicos da inovação tecnológica: aspectos constitucionais, administrativos, tributários e processuais. Rio de Janeiro: Lumen Juris, 2018. Prefácio.

TORKOMIAN Ana Lúcia Vitale (coord.). Relatório anual da Pesquisa FORTEC de Inovação: ano base 2017. [2018]. Disponível em: http://fortec.org.br/wp-content/uploads/2019/05/Relatório_anual_ Ano_Base_2017.pdf. Acesso em: 11 jul. 2019.

TRZECIAK, Dorzeli Salete; CORAL, Eliza; PEREIRA, Guilherme Luiz (org.). Estruturação e Planejamento de Núcleos de Inovação Tecnológica. 2010. Disponível em: https://brasil.abgigroup.com/wp-content/uploads/2010/10/Manual_PlanejamentoNITs-FINAL.pdf. Acesso em: 11 jul. 2019.

UEL - UNIVERSIDADE ESTADUAL DE LONDRINA. Resolução CU n. 0065/2008. Dispõe sobre a Criação da Agência de Inovação Tecnológica da Universidade Estadual de Londrina. Disponível em: https://sistemas.uel.br/files/atonormativo/RESOLUCOES/2008/65.pdf. Acesso em: 12 jul. 2019.

UEL - UNIVERSIDADE ESTADUAL DE LONDRINA. Resolução CU n. 0263/2009. Aprova o Regimento da Agência de Inovação Tecnológica da Universidade Estadual de Londrina - AINTEC. Disponível em: https://sistemas.uel.br/files/atonormativo/RESOLUCOES/2009/263.pdf. Acesso em: 12 jul. 2019.

UEL - UNIVERSIDADE ESTADUAL DE LONDRINA. Resolução CU n. 034/2017. Aprova o Regimento da Agência de Inovação Tecnológica da Universidade Estadual de Londrina - AINTEC. Disponível em: https://sistemas.uel.br/files/atonormativo/RESOLUCOES/2017/34.pdf. Acesso em: 08 jul. 2019.

UEL - UNIVERSIDADE ESTADUAL DE LONDRINA. Resolução CU n. 1.312/1988. Aprova a participação de docentes e servidores técnico-administrativos no resultado financeiro da exploração de patentes da Universidade Estadual de Londrina. Disponível em: https://sistemas.uel.br/files/ atonormativo/RESOLUCOES/1988/1312.pdf. Acesso em: 12 jul. 2019.

UEL - UNIVERSIDADE ESTADUAL DE LONDRINA. UEL em dados 2019. [2019]. Disponível em: http://www.uel.br/proplan/novo/pages/arquivos/uel_em_dados/UEL-em-dados_2019.pdf. Acesso em: 7 jul. 2019.

VON JELITA, Roberto Roberval Ritter et al. Núcleos de Inovação Tecnológica. In: BOCCHINO, Leslie de Oliveira et al. Publicações da Escola da AGU: Propriedade Intelectual - conceitos e procedimentos, Brasília, DF: Advocacia-Geral da União, 2012. v. 2, ano IV, n. 14. p. 127-150. 


\section{Sobre os Autores}

\section{Mario Cesar Lobo Junior}

E-mail:mario.cesar@uel.br Graduando da Faculdade de Direito da Universidade Estadual de Londrina.

Endereço profissional: Universidade Estadual de Londrina, Centro de Estudos Sociais Aplicados, Rodovia Celso Garcia Cid, PR 445, km 380, Campus Universitário, Londrina, PR. CEP: 86.057-970.

\section{Letícia de Souza Baddauy}

E-mail: leticia@uel.br

Mestre em Direito Processual Civil pela Universidade Estadual de Londrina em 2006. MBA em Agronegócio pela Escola Superior de Agricultura Luiz de Queiroz, da Universidade de São Paulo (ESALQ/USP) em 2020. Especialista em Direito Penal Econômico Internacional pela Universidade de Coimbra em 2001.

Endereço profissional: Universidade Estadual de Londrina, Centro de Estudos Sociais Aplicados, Departamento de Direito Público, Rodovia Celso Garcia Cid, PR 445, km 380, Campus Universitário, Londrina, PR. CEP: 86.057-970. 